\title{
ESTUDIO COMPARATIVO SOBRE LA MORFOLOGIA DE TRIALEURODES VAPORARIORUM (WESTWOOD) Y BEMISIA TABACI (GENNADIUS) (HEMIPTERA: ALEYRODIDAE)
}

\author{
VICENTE EMILIo CARAPIA RUIZ ${ }^{1} \&$ ANTONIo CASTILLO-GUTIÉRREZ \\ ${ }^{1}$ Universidad Autónoma del Estado de Morelos, Instituto Profesional de la Región Oriente. Xalostoc, \\ Villa de Ayala, Morelos, CP 62715, México.<vcarapia@hotmail.com>
}

Carapia R., V. E. \& Castillo-Gutiérrez, A. 2013. Estudio comparativo sobre la morfología de Trialeurodes vaporariorum (Westwood) y Bemisia tabaci (Gennadius) (Hemiptera: Aleyrodidae). Acta Zoológica Mexicana (n. s.), 29(1): 178-193.

RESUMEN. Se presenta un estudio morfológico comparativo de las diferentes etapas de desarrollo entre la mosquita blanca del tabaco Bemisia tabaci (Gennadius) y de la mosquita blanca del invernadero Trialeurodes vaporariorum (Westwood); para ilustrar se incluyen dibujos y microfotografías en contraste de fases.

Palabras clave: Morfología, mosquita blanca, Bemisia tabaci, Trialeurodes vaporariorum.

Carapia R., V. E. \& Castillo-Gutiérrez, A. 2013. Morphological comparision between Trialeurodes vaporariorum (Westwood) and Bemisia tabaci (Gennadius) (Hemiptera: Aleyrodidae). Acta Zoológica Mexicana (n. s.), 29(1): 178-193.

ABSTRACT. A morphological comparison of the tobacco whitefly Bemisia tabaci (Gennadius) and the greenhouse whitefly Trialeurodes vaporariorum (Westwood) is reported and illustrated by phase contrast microphotographs and drawings.

Key words: Morphology, whiteflies, Bemisia tabaci, Trialeurodes vaporariorum.

\section{INTRODUCCIÓN}

Se estima que la familia Aleyrodidae cuenta con más de 1200 especies descritas; las mosquitas blancas (Hemiptera: Aleyrodidae) son pequeños insectos fitófagos de plantas herbáceas, arbustos, árboles, plantas silvestres y cultivos de importancia económica; en ocasiones se convierten en un serio problema, debido en primera instancia a daños directos provocados al succionar la savia y por la transmisión de virus. Actualmente dos especies de importancia económica presentan una alta similitud, no obstante que se encuentran en géneros diferentes, éstas son Bemisia tabaci (Gennadius) y Trialeurodes vaporariorum (Westwood).

Recibido: 14/06/2012; aceptado: 16/11/2012. 
Aunque Hill (1969), con su trabajo morfológico clarificó la incertidumbre y confusión que existía en cuanto a la identidad del insecto vector de la enfermedad virosa del chino de la hoja del tabaco (Tobaco Leaf Curl Virus) en Sudáfrica, indicando a Bemisia tabaci como el vector y no a Trialeurodes vaporariorum; sin embargo, el autor en varios caracteres presenta diferencias con respecto a especímenes de este estudio de considerable atención, como es el caso de los cepillos de las tibias medias y posteriores, las sensilas primarias y cono sensorial en el sexto segmento antenal.

En México ha sucedido una situación similar a lo ocurrido en Sudáfrica; desde 1970 se observaron síntomas causados por el virus del chino del tomate en cultivos de este producto en el estado de Sinaloa y se presentaron epidemias de esa enfermedad entre 1970 y 1983, y anualmente desde 1988; según Brown y Nelson (1988), el problema se debió a la presencia de altas poblaciones de $B$. tabaci. En el estado de Morelos, una enfermedad del tomate que presenta síntomas del virus del chino del tomate y que es transmitido por mosquita blanca, ha tenido incertidumbre en cuanto a la identificación del vector de la enfermedad, ya que en cualquier etapa de desarrollo del cultivo del tomate se pueden encontrar las dos especies, $T$. vaporariorum y $B$. tabaci. Estas son muy parecidas, provocando problemas de identificación errónea de la especie de mosca blanca, como el caso de Hernández (1972), quien publicó fotografías de pupas y adultos identificados equivocadamente como T. vaporariorum, y que corresponden a B. tabaci (Carapia, 1991).

Estudios en Bemisia tabaci realizados por Azab et al. (1969) muestran una pobre descripción morfológica de adultos de esta especie comparado con el estudio de Hill (1969). Lima et al. (2001) con base en fotografía electrónica de barrido, mostró algunos aspectos interesantes de Bemisia argentifollii (B. tabaci, biotipo B) como los peines metatibiales; sin embargo, al no considerar los antecedentes sobre la morfología de $B$. tabaci, no da mayor atención a más estructuras morfológicas que complementarían la caracterización y facilitarían la distinción de $B$. tabaci. Debido a la alta cantidad de incongruencias en la morfología de los especímenes estudiados en las diversas publicaciones, se tiene la necesidad de realizar una nueva descripción morfológica comparativa de B. tabaci y $T$. vaporariorum.

\section{MATERIAL Y METÓDOS}

Colecta de especímenes y plantas hospedantes. Los especímenes fueron capturados directamente del hospedante, para el caso de $T$. vaporariorum se recolectó en frijol (Phaseolus vulgaris L.) y pepino (Cucumis sativus L.); en tanto que los especímenes de B. tabaci se capturaron en tomate (Lycopersicon esculentum P. Mill) y noche buena (Poinsettia pulcherrima (Willd. ex Klotzsch) Graham). Todas las colectas se realizaron en el estado de Morelos y el material fue preservado en alcohol al 70\%; el 
material procesado e identificado se encuentra despostado en la Colección de Insectos de la Universidad Autónoma del Estado de Morelos.

\section{Preparación de especímenes en portaobjetos para observación al microscopio.} Los métodos para la preparación de especímenes (larvas y pupas) en portaobjetos más comúnes son las de Bink (1979), similar a la de Martin (1987), las cuales son la base del siguiente procedimiento:

1. Maceración de pupas en hidróxido de potasio al $40 \%$ durante un lapso de 20 a 60 minutos en un vidrio de reloj; para las cubiertas pupales de las que han emergido los adultos, se pasa directamente al paso tres.

2. Lavado de pupas en agua destilada durante 15 minutos.

3. Deshidratado de pupas en cloral-fenol (hidrato de cloral 1 parte: fenol 1 parte) por 60 minutos a $40{ }^{\circ} \mathrm{C}$, enseguida pasar a ácido acético glacial por $5 \mathrm{~min}$.

4. Teñido con fushina ácida ( $5 \mathrm{~min}$ ), enseguida pasar a ácido acético glacial por 5 min.

5. Inmersión en esencia de clavo para las preparaciones en bálsamo de Canadá por 2 h o más.

6. Montaje en bálsamo de Canadá u Hoyer, en este último caso se sella con esmalte.

Los adultos se montaron en bálsamo de Canadá a partir de Cellosolve (Etilen glicol monoetil éter).

Observaciones, mediciones, fotografía y gráficos. Los especímenes inmaduros, pupas y adultos fueron examinadas en un microscopio estereoscópico a 40 aumentos antes de someterlas al proceso de montaje en portaobjetos según la metodología descrita por Martín (1987). Posteriormente las preparaciones se revisaron en un microscopio con contraste de fases Motic BA 310 a 40, 100, 400 y 1000 aumentos. Las medidas se hicierón con un micrómetro adaptado a un ocular que previamente se calibró. La toma de fotografías fue con una cámara digital integrada al mismo microscopio, algunas fotografías impresas se utilizaron como base para dibujo gráfico de ciertas estructuras.

\section{RESULTADOS Y DISCUSIÓN}

En el Cuadro 1 se puede apreciar un resumen comparativo de la morfología de $T$. vaporariorum y $B$. tabaci; posteriormente se describirá la morfología de cada una de las etapas de desarrollo de manera simultánea en ambas especies. 
Cuadro 1. Características distintivas y entre Trialeurodes vaporariorum y Bemisia tabaci en sus diferentes etapas de desarrollo.

\begin{tabular}{|c|c|c|}
\hline Etapa y estructura & Trialeurodesvaporariorum & Bemisiatabaci \\
\hline \multicolumn{3}{|l|}{ Huevo } \\
\hline Corion & Oscuro con el ápice doblado & $\begin{array}{l}\text { Marrón dorado con ápice no } \\
\text { doblado }\end{array}$ \\
\hline \multicolumn{3}{|l|}{ Larva de primer instar } \\
\hline Orificio vasiforme & Cuadrangular en parte posterior & Redondeado en parte posterior \\
\hline Parte apical de la língula & Ancha con setas aparentes & Aguda sin setas \\
\hline \multicolumn{3}{|l|}{ Larva de segundo instar } \\
\hline Língula & Con dos lóbulos laterales & Aguda sin lóbulos \\
\hline \multicolumn{3}{|l|}{ Larva de tercer instar } \\
\hline Língula & Con tres lóbulos laterales & Aguda sin lóbulos \\
\hline \multicolumn{3}{|l|}{ Larva de cuarto instar y pupa } \\
\hline Forma del cuerpo & Elíptica & Semitriangular \\
\hline Orificio vasiforme & Semicordiforme & Triangular \\
\hline Língula & Lobulada & Aguda no lobulada \\
\hline Setas dorsales & Ausentes & $\begin{array}{l}\text { Presentes en algunos } \\
\text { especímenes }\end{array}$ \\
\hline Filamentos de cera & $\begin{array}{l}\text { Presentes (se pierden al realizar } \\
\text { preparaciones) }\end{array}$ & Ausentes \\
\hline Surco caudal & No aparente & Presente bien definido \\
\hline \multicolumn{3}{|l|}{ Pliegues traqueales torácicos } \\
\hline y caudal & No aparentes & Presente bien definidos \\
\hline \multicolumn{3}{|l|}{ Adulto } \\
\hline Ojos compuestos & Superior e inferior separados & Superior e inferior unidos por \\
\hline $\begin{array}{l}\text { Cono sensorial del tercer } \\
\text { segmento antenal }\end{array}$ & $\begin{array}{l}\text { Cerca de la parte terminal } \\
\text { muy próximo a las sensilas } \\
\text { primarias }\end{array}$ & $\begin{array}{l}\text { una omatidia } \\
\text { Claramente ubicado antes y } \\
\text { en línea con las sensilas } \\
\text { primarias }\end{array}$ \\
\hline $\begin{array}{l}\text { Cono sensorial del cuarto } \\
\text { segmento antenal }\end{array}$ & Presente & Ausente \\
\hline Tibias mesotorácicas & $\begin{array}{l}\text { Dos cepillos de } 3 \text { a } 5 \text { espinas } \\
\text { uno opuesto al otro en la } \\
\text { parte media }\end{array}$ & Sin cepillos de 3 a 5 espinas \\
\hline Tibias metatorácicas & $\begin{array}{l}\text { Con un cepillo de } 4 \text { a } 5 \text { espinas } \\
\text { opuesto a la parte final del } \\
\text { peine de espinas }\end{array}$ & $\begin{array}{l}\text { Sin un cepillo de } 4 \text { a } 5 \text { espinas } \\
\text { opuesto a la parte final del } \\
\text { peine de espinas }\end{array}$ \\
\hline
\end{tabular}

\section{Huevo}

Trialeurodes vaporariorum. Dimensiones: $200-250 \mu \mathrm{m}$ de longitud y $100 \mu \mathrm{m}$ de ancho (Fig. 1a). Generalmente son puestos en círculos o semicírculos sobre la superficie de la hoja; sin embargo, cuando la infestación es alta esto es muy difícil de 

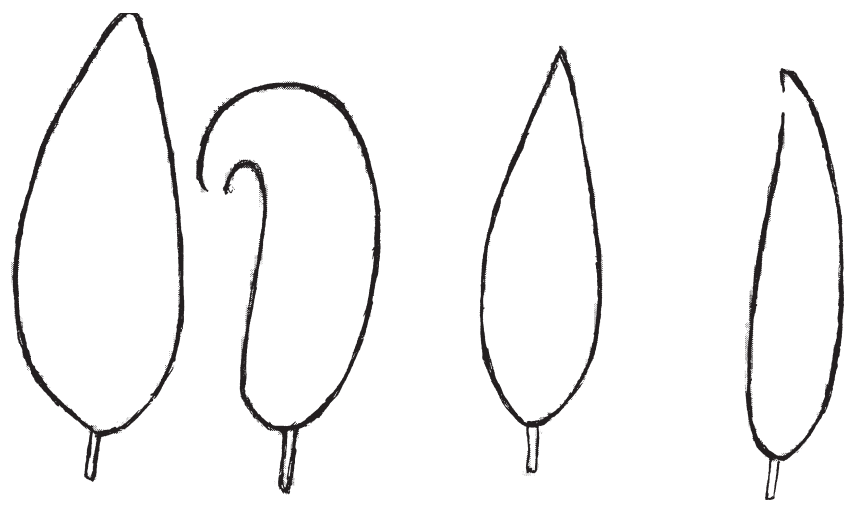

Fig. 1. Huevo, a) Trialeurodes vaporariorum, b) Bemisia tabaci; izquierda corion.

apreciar; de color blanco amarillento cuando son puestos, tornándose castaño oscuro a casi negro cuando están próximos a eclosionar; el corion del cual emergió la larva, se aplana lateralmente y se dobla con el ápice dirigido hacia abajo.

Bemisia tabaci. Dimensiones: 190-200 $\mu \mathrm{m}$ de longitud y de 100-129 $\mu \mathrm{m}$ de ancho (Fig. 1b). Ovipositados individualmente o en grupos sobre la superficie de la hoja, raramente son puestos en círculo; de color blanco amarillento, tornándose marrón dorado en su etapa final. Al emerger la larva el corión del huevo permanece erecto.

\section{Primer estadio larval}

Trialeurodes vaporariorum. Dimensiones: $240-270 \mu \mathrm{m}$ de largo y $150 \mu \mathrm{m}$ de ancho. Estado de desarrollo activo en locomoción y se desplaza en busca de un lugar adecuado para alimentación por lo que sus patas y antenas son relativamente grandes (Fig. 2a); presenta 17 pares de sedas marginales muy aparentes; sedas marginal anterior, marginal posterior, cefálica, primera abdominal octava abdominal y caudal presentes; tubérculos cefálicos bien desarrollados, semirectangulares abiertos hacia la parte media (Fig. 2b); orificio vasiforme cuadrangular posteriormente (Fig. 2c).

Bemisia tabaci. Dimensiones: 250- $300 \mu \mathrm{m}$ de largo y $155 \mu \mathrm{m}$ de ancho. Como en T. vaporariorum, es un estado de desarrollo activo en locomoción y se desplaza en busca de un lugar adecuado para alimentación por lo que sus patas y antenas son relativamente grandes; presenta 16 pares de sedas marginales aparentes; sedas marginal anterior, marginal posterior, cefálica, primera abdominal, octava abdominal y caudal presentes; tubérculos cefálicos poco desarrollados, semielípticos hacia la parte lateral (Fig. 3a); orificio vasiforme curvo posteriormente (Fig. 3b). 

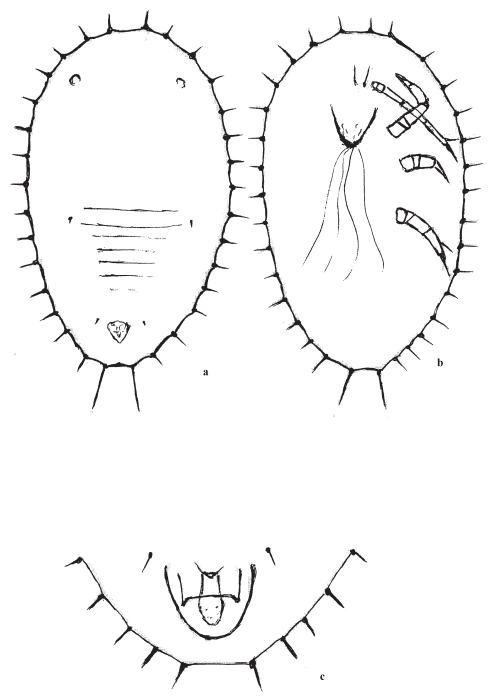

Fig. 2. Trialeurodes vaporariorum, larva de primer instar: a) vista ventral, b) vista dorsal, c) orificio vasiforme.
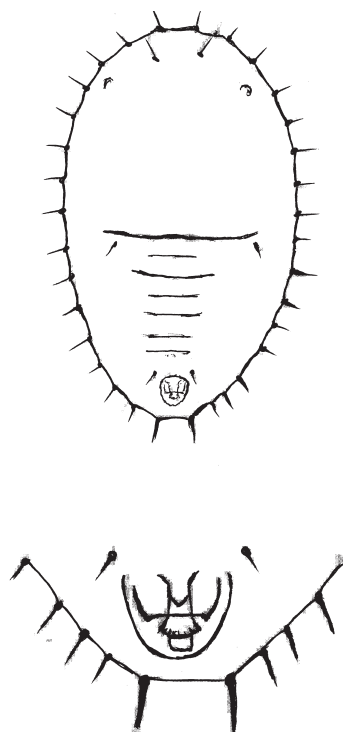

Fig. 3. Bemisia tabaci, larva de primer instar; a) vista ventral, b) orificio vasiforme.

\section{Larvas de segundo estadio}

Trialeurodes vaporariorum. Dimensiones: $420 \mu \mathrm{m}$ de largo y $330 \mu \mathrm{m}$ de ancho. Cuerpo redondeado, no agudo posteriormente; sedas marginal anterior, marginal posterior, cefálica, primera abdominal, octava abdominal y caudal presentes; seda dorsal del segmento cefálico bien desarrollada; pliegues torácicos traqueales no indicados ventralmente (Fig. 4a); orificio vasiforme semicordiforme; língula con dos lóbulos laterales (Fig. 4b).

Bemisia tabaci. Dimensiones: $0.38 \mu \mathrm{m}$ de largo por $0.24 \mu \mathrm{m}$ de ancho. Cuerpo ovoide, agudo posteriormente; sedas marginal anterior, marginal posterior, cefálica, primera abdominal, octava abdominal y caudal presentes; pliegues torácico traqueales indicados ventralmente por una cutícula punteada (Fig. 5a); orificio vasiforme triangular, abierto posteriormente; língula ensanchada y puntiaguda distalmente pero no lobulada (Fig. 5b).

\section{Larvas de tercer estadio}

Trialeurodes vaporariorum. Dimensiones: 560-600 $\mu \mathrm{m}$ de largo y $400 \mu \mathrm{m}$ de ancho. Margen del cuerpo uniformemente granulado; pliegue torácico traqueal no indicado 

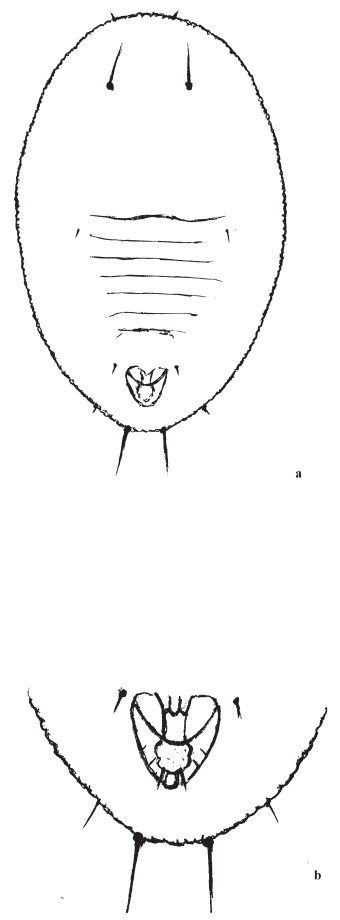

Fig. 4. Trialeurodes vaporariorum, larva de segundo instar: a) vista ventral, b) orificio vasiforme.
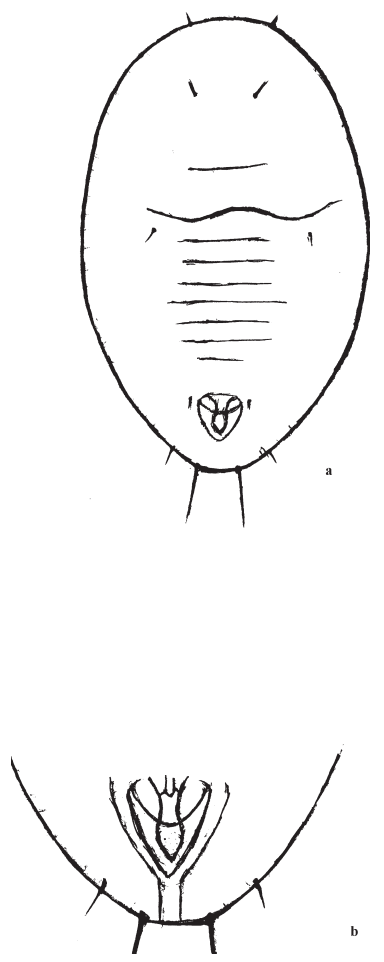

Fig. 5. Bemisia tabaci, larva de segundo instar: a) vista ventral, b) orificio vasiforme.

ventralmente; sedas marginal anterior, marginal posterior, cefálica, primera abdominal, octava abdominal y caudal presentes (Fig. 6a). Orificio vasiforme semicordiforme con una muesca en la parte media posterior a la língula; língula lobulada lateralmente, con dos pares de lóbulos (Fig. 6b).

Bemisia tabaci. Dimensiones: 500-540 $\mu \mathrm{m}$ de largo y $360 \mu \mathrm{m}$ de ancho. Margen irregularmente granulado; pliegue torácico traqueal indicado por una cutícula punteada ventralmente; sedas marginal anterior, marginal posterior, cefálica, primera abdominal, octava abdominal y caudal presentes (Fig. 7a); orificio vasiforme triangular; língula ensanchada y puntiaguda distalmente pero no lobulada (Fig. 7b).

\section{Larvas de cuarto estadio (y pupario)}

Trialeurodes vaporariorum. Dimensiones: $780-800 \mu \mathrm{m}$ de largo y $510 \mu \mathrm{m}$ de ancho. Pupas vivas con la superficie dorsal elevada por la palizada de la superficie ventral, 

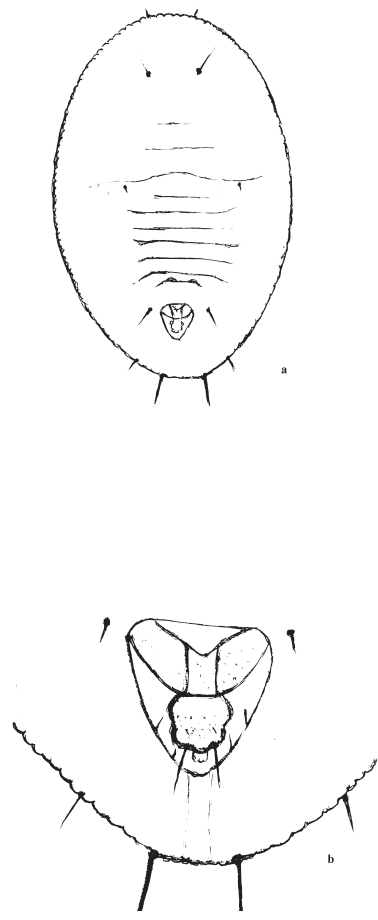

Fig. 6. Trialeurodes vaporariorum, larva de tercer instar: a) vista ventral, b) orificio vasiforme.
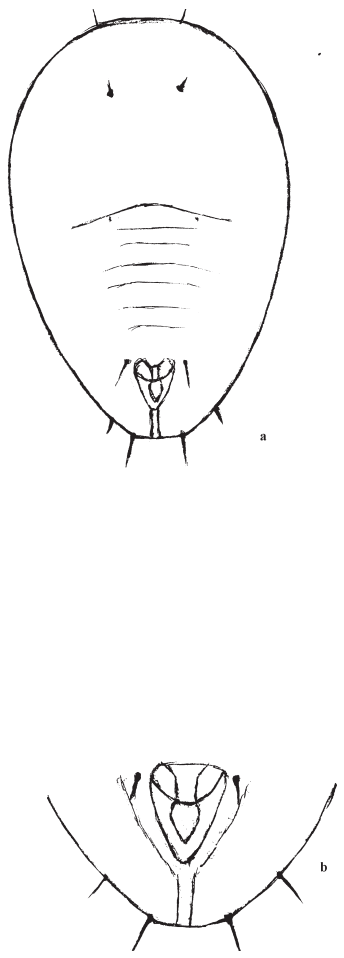

Fig. 7. Bemisia tabaci, larva de tercer instar: a) vista ventral, b) orificio basiforme.

la cual está sobre la superficie de la hoja; superficie dorsal con cubierta y varillas de cera blanquecina, área submarginal con filamentos cortos de cera; superficie ventral y lateral con cubierta de cera. Los especímenes son de forma elíptica, redondeados posteriormente; papilas dorsales y submarginales presentes; margen uniformemente granulado; área porosa traqueal torácica y caudal se diferencian distintivamente en el margen; antenas situadas lateralmente de las patas protorácicas; sedas marginal anterior, marginal posterior, cefálica, primera abdominal, octava abdominal y caudal presentes (Fig. 8a); pliegue torácico traqueal no indicado ventralmente; orificio vasiforme semicordiforme; língula lobulada (Fig. 8b).

Bemisia tabaci. Dimensiones: $750-850 \mu \mathrm{m}$ de largo y $620 \mu \mathrm{m}$ de ancho. Pupas vivas sin palizada de cera y también las varillas de cera están ausentes, son de color amarillento. Especímenes montados de forma semioval, agudos posteriormente; series de papilas submarginales ausentes; puede presentar sedas dorsales largas y bien desarrolladas especialmente en especímenes que se desarrollaron en hojas con pubescencia 
como es reportado previamente por Russell $(1947,1948)$. Margen irregularmente granulado; poros traqueales no diferenciados en el margen; pliegues torácicos traqueales distintivamente en la superficie ventral por una cutícula punteada; antenas situadas al lado de las patas protorácicas. Sedas marginal anterior, marginal posterior, cefálica, primera abdominal, octava abdominal y caudal presentes (Fig. 9a); orificio vasiforme triangular; língula ensanchada y puntiaguda distalmente (Fig. 9b).

\section{Adulto}

Trialeurodes vaporariorum. Dimensiones: 0.75 a $1.10 \mathrm{~mm}$ de largo. Los adultos vivos tienen el cuerpo de un color amarillo pálido, con dos pares de alas blancas inmaculadas (Fig. 10a). Los ojos compuestos están divididos y no hay algún omatidio que forme un puente entre los dos grupos de facetas (Fig. 10b). Las antenas (Fig. 12, 17b) con una sensila primaria en los segmentos 3,5 y 7 . Un cono sensorial, está presente en los segmentos 3, 6 y 7, es similar a las de Bemisia tabaci pero en esta última espe-
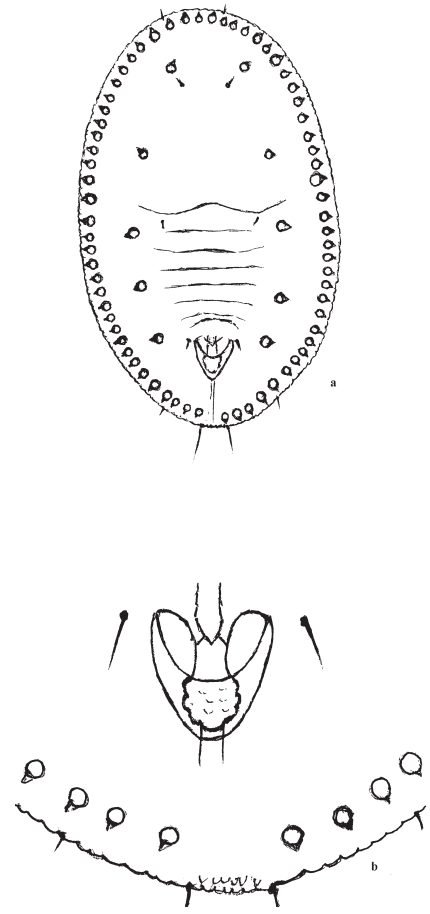

Fig. 8. Trialeurodes vaporariorum, larva de cuarto instar (pupa): a) vista ventral, b) orificio vasiforme.
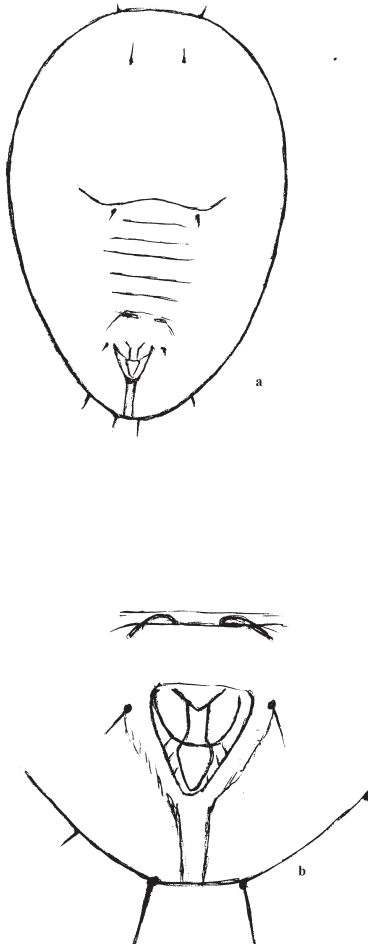

Fig. 9. Bemisia tabaci, larva de cuarto instar (pupa): a) vista ventral, b) orificio vasiforme. 


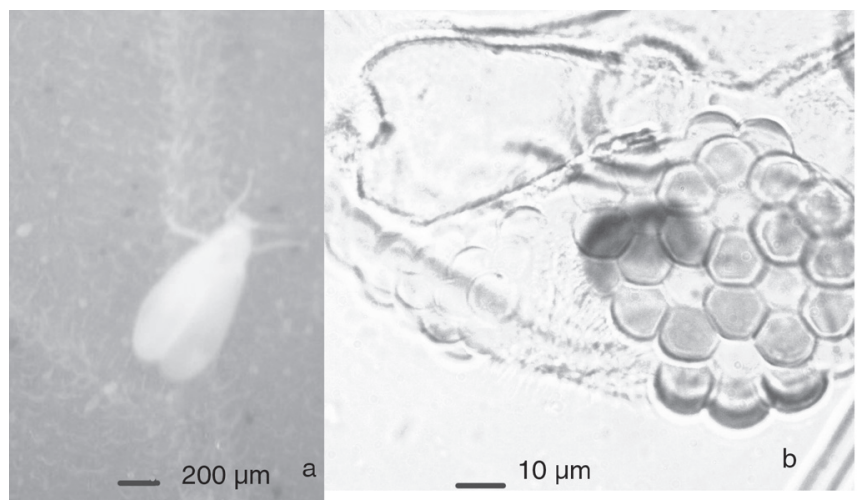

Fig. 10. Trialeurodes vaporariorum, adulto: a) alas con techo a dos aguas, b) ojo compuesto superior e inferior separados.

cie hay una sensila primaria en el segmento cuatro, algunas sensilas como ésta son difíciles de ver lo que podría explicar que Hill (1969) indicara que este segmento carece de ésta. Las antenas de $T$. vaporariorum, son ligeramente y en forma consistente más grandes que las de $B$. tabaci; también las antenas de la hembra y macho en ambas especies son muy similares en tamaño, sólo que en algunos especímenes las de las hembras son ligeramente más largas, no acorde con lo esquematizado por Gill (1990).

Alas anteriores con el margen anterior curvado y redondeado distalmente; el margen de las alas anteriores "perillada" (Fig. 16a). Hill (1969) reporta el borde del ala desnuda para esta especie, pero análisis de varios especímenes de diferentes localidades indican la presencia de pequeñas sedas como en $B$. tabaci. Las espinas gruesas en la tibia meso y metatorácica son distintivamente arregladas en dos cepillos, uno opuesto al otro en las tibias medias y uno opuesto al peine en la tibia posterior (Fig. 11a, 11b, 14a). En una amplia descripción de esta especie de Hill (1969) las tibias son registradas de otra forma.

Las placas cerosas están presentes en la superficie ventral abdominal, dos para hembras y cuatro para los machos (Fig. 13), la superficie de estas estructuras es semirreticulada contrario a lo que menciona y esquematiza Hill (1969). La placa supra genital está bien desarrollada y claramente definida en la hembra; en el macho está modificada en un cuello en forma de tubo que es fuertemente esclerosada y oscuramente pigmentada (Fig. 13). El abdomen del macho presenta cinco bandas de poros de 2-4 $\mu \mathrm{m}$ de diámetro, en la superficie dorsal. El orificio vasiforme está situado en la placa supra-genital y es similar en tamaño y forma en ambas especies. El edeago del macho de T. vaporariorum es ligeramente más largo que en B. tabaci y más ancho sobre todo en la mitad basal; el borde ventral es casi recto (Fig. 20). 




Fig. 11. Trialeurodes vaporariorum, adulto: a) tibia posterior, b) tibia media.

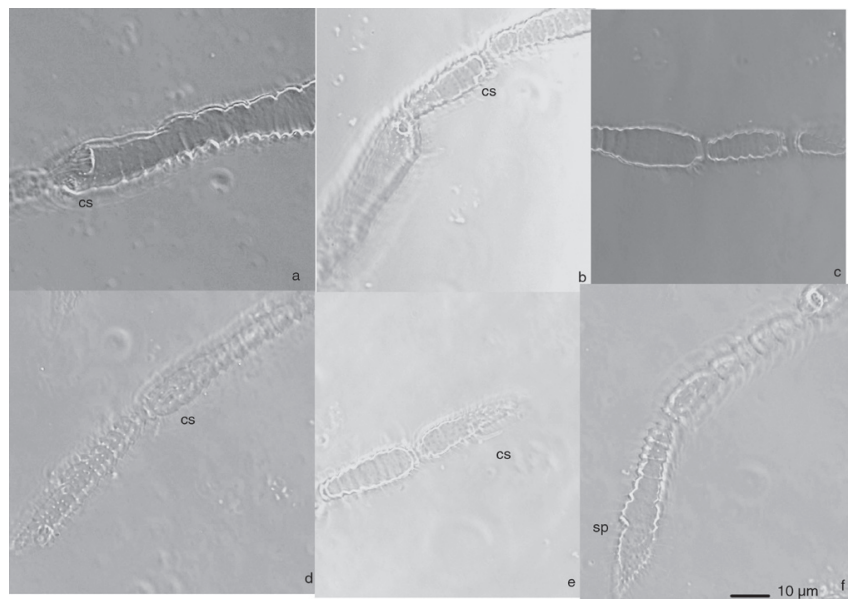

Fig. 12. Trialeurodes vaporariorum, sensilas primarias (sp) y conos sensoriales (cs), a) segmento 3, b) segmento 4, c) segmento 5, d) segmento 6, e y f) segmento 7 .

Bemisia tabaci. Tamaño de 0.70 a $0.95 \mathrm{~mm}$ de largo. Los adultos vivos tienen el cuerpo de color amarillo oscuro, con dos pares de alas blancas inmaculadas. Ojos compuestos divididos y cada ojo consiste en dos grupos de omatidias con un omatidio que forma un puente entre los dos grupos (Fig. 18b). Para el ojo compuesto Lima et al. (2001), reportan en forma clara que la parte superior está formada por 45 omatidias y la porción inferior por 31 omatidias, arregladas en forma hexagonal, en grupos interconectados de 6 omatidias alrededor de una omatidia relativamente un poco menor y generalmente de color más claro. Las antenas (Fig. 21, 17a), constan de 


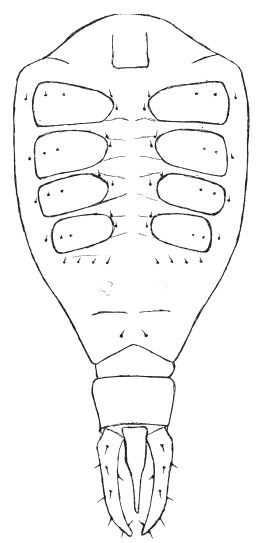

Fig. 13. Trialeurodes vaporariorum, abdomen de macho en vista ventral.
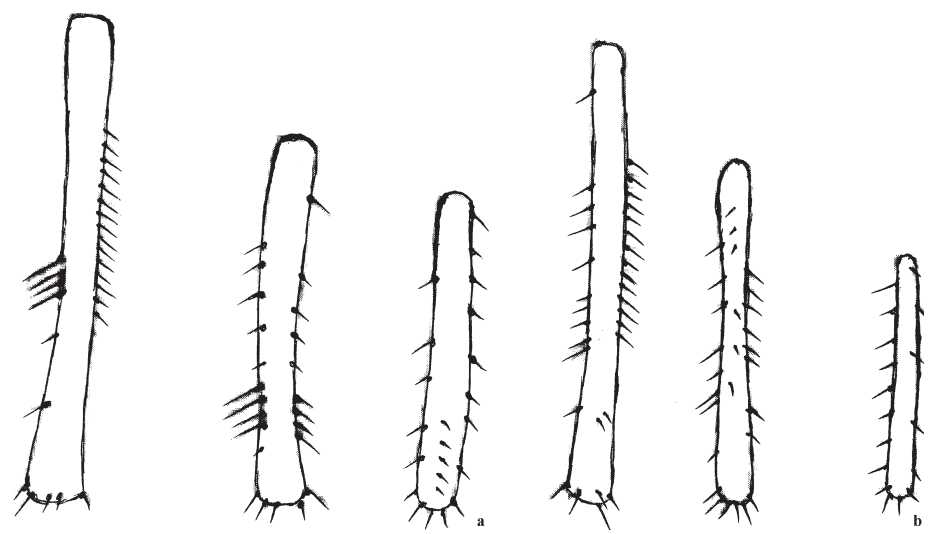

Fig. 14. Tibia posterior, media y anterior, a) Trialeurodes vaporariorum, b) Bemisia tabaci.

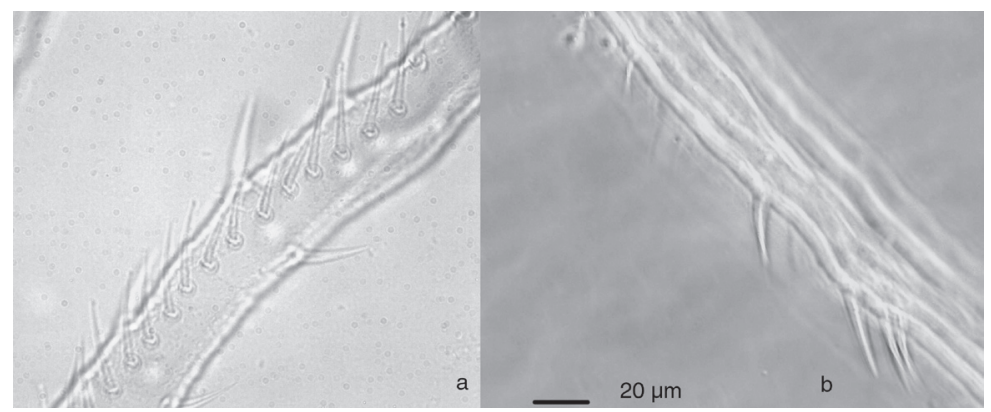

Fig. 15. Bemisia tabaci, a) tibia posterior, b) tibia media. 


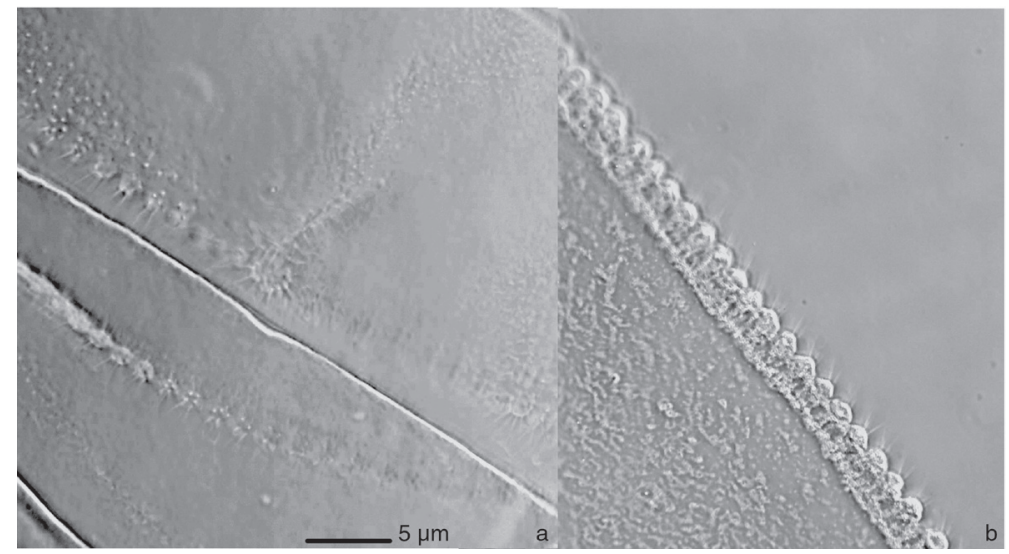

Fig. 16. Borde del ala, a) Trialeurodes vaporariorum, b) Bemisia tabaci.

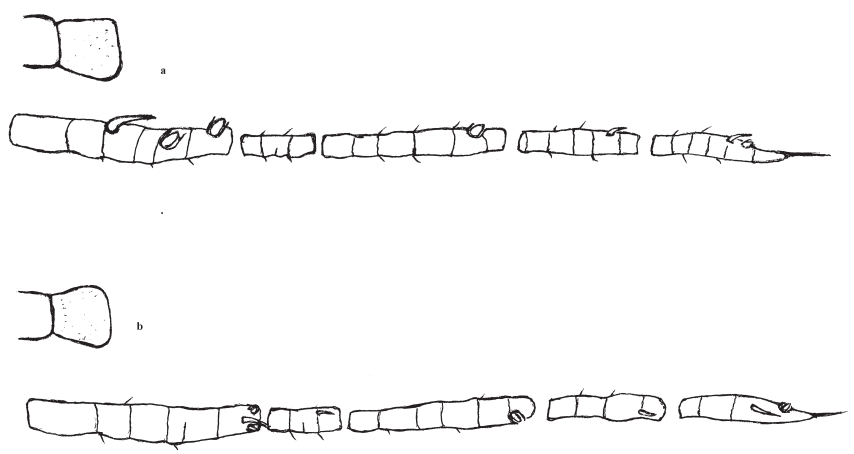

Fig. 17. Antenas, a) Bemisia tabaci, b). Trialeurodes vaporariorum.

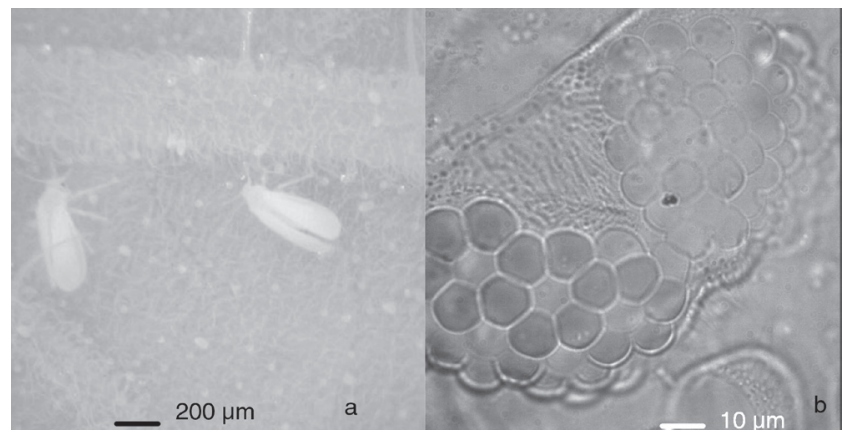

Fig. 18. Bemisia tabaci, a) adulto con alas muy inclinadas, b) ojo compuesto superior e inferior unido con una omatidia. 

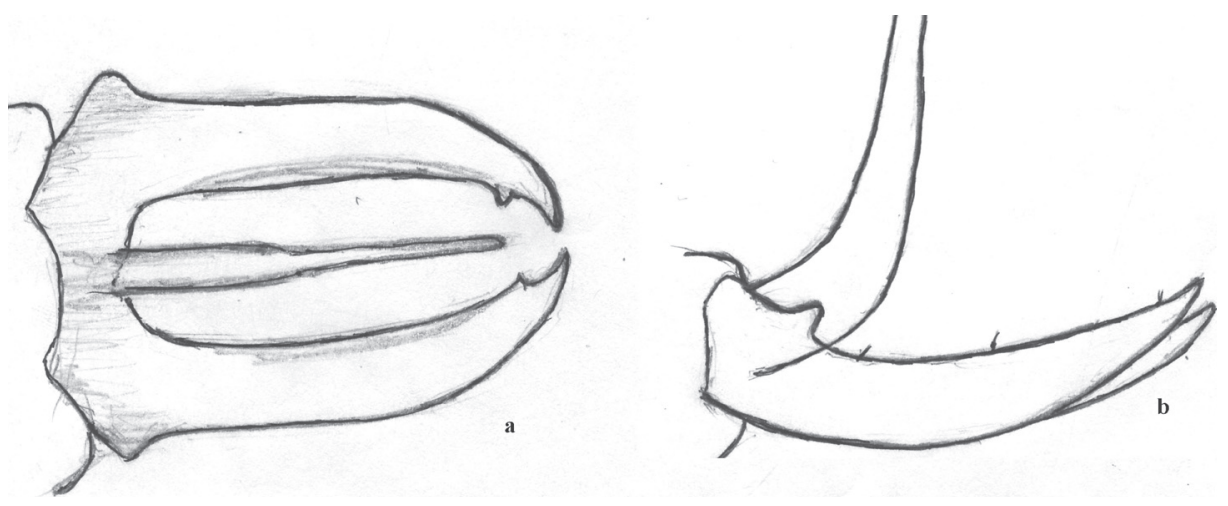

Fig. 19. Bemisia tabaci, genitalia del macho (parameros y aedeago), a) vista dorsal, b) vista lateral.
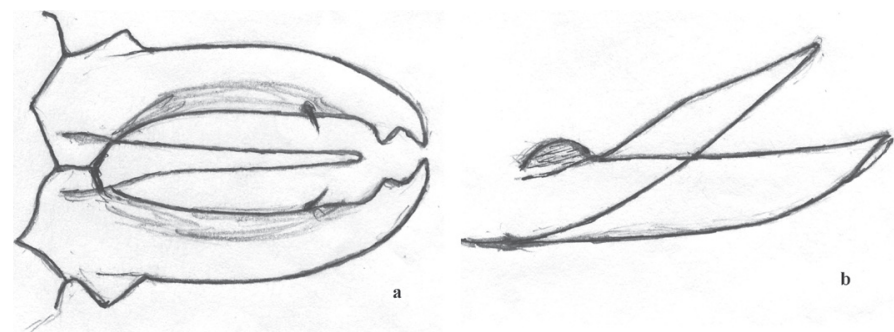

Fig. 20. Trialeurodes vaporariorum, genitalia del macho (parámeros y aedeago), a) vista dorsal, b) vista lateral.

siete segmentos con una sensila primaria en los segmentos 3, 5 y 7. Cono sensorial, está presente en el segmento 3, 6 y 7. Hill (1969) reporta la mayoría de las sensilas en forma correcta; sin embargo, en el segmento 6 ilustra incorrectamente una sensoria primaria.

Las alas son membranosas y desnudas, presentando textura semejante, margen anterior de las alas anteriores recto, redondeado distalmente, con venación notablemente reducida, mantenidas ligeramente separadas, formando una especie de techo a dos aguas muy inclinadas sobre el abdomen (Fig. 18a), dejando parte del abdomen visible. El margen de las alas anteriores y posteriores es "perillada" con setas diminutas originándose de cada estructura (Fig. 16b). Previamente Hill (1969) reportó esta característica con dos sedas diminutas (en vista lateral); sin embargo, presenta de cuatro a seis. Las tibias de las patas mesotorácicas presentan espinas fuertes que se disponen en forma aleatoria, característica que no es acorde con lo esquematizado por Hill (1969) ya que la descripción ilustrada de las tibias es de forma muy diferente aparentando ser las de T. vaporariorum pero con el peine metatibial muy corto. Patas 


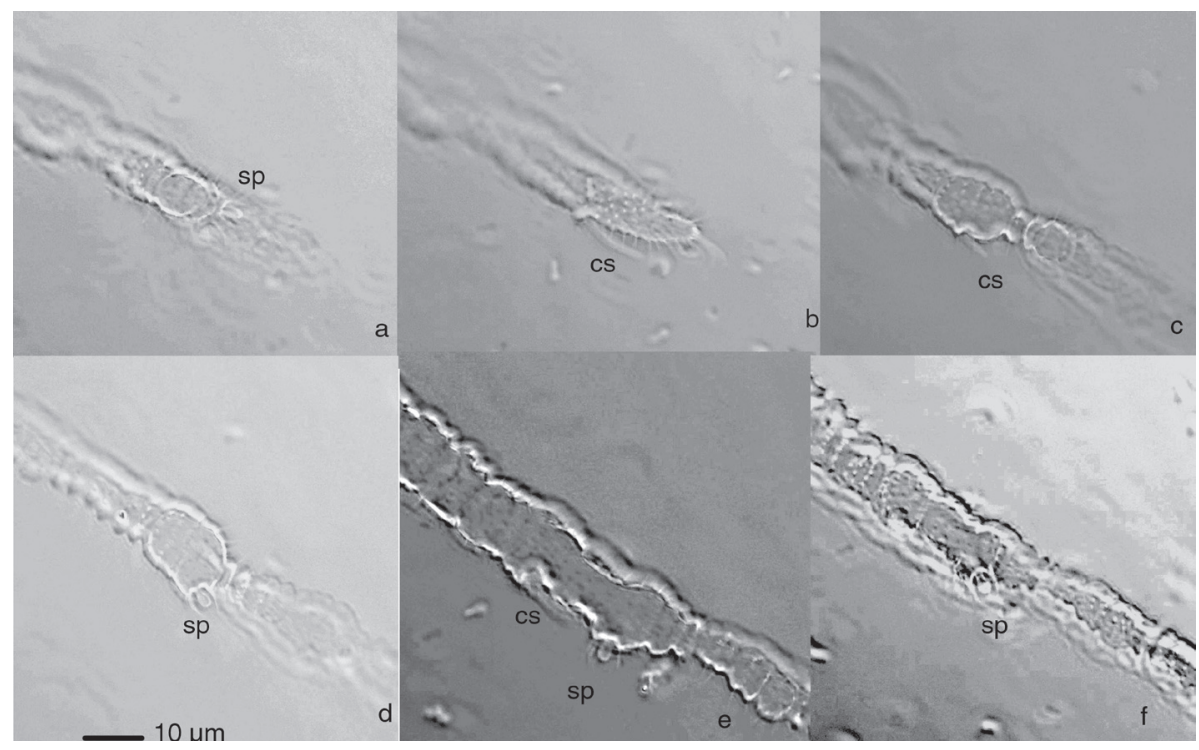

Fig. 21. Bemisia tabaci, sensilas primarias (sp) y conos sensoriales(cs), a) segmento 7 , b) segmento $7, \mathrm{c}$ ) segmento 6 , d) segmento 5 , e y f) segmento 3 .

metatorácicas con un único grupo lineal de setas; las cuales son normalmente más pequeñas, menos gruesas y esclerotizadas y más juntas que otras setas sobre el mismo segmento de la pata (Fig. 14b, 15). Estas setas son llamadas peines metatibiales (Gill, 1990). Lima et al, (2001) reportan una imagen de un peine de setas con 17 unidades, las cuales pueden variar ligeramente en número. En la superficie ventral del abdomen de las hembras están presentes dos pares de placas cerosas en los segmentos tres y cuatro, en el caso de los machos se presentan cuatro pares en los segmentos tres a seis.

La superficie de las placas cerosas (Fig. 22) del abdomen es semirreticulada con figuras similares a rombos ocupando cada uno aproximadamente un $\mu \mathrm{m}$ de la superficie; la placa supra genital es débilmente desarrollada en la hembra y en el macho esta modificado en un cuello en forma de tubo que es proyectado del ápice del abdomen y lleva los genitales del macho distalmente. El edeago del macho en $B$. tabaci es ligeramente más corto que en $T$. vaporariorum y más delgado y un poco sinuoso como se ilustra (Fig. 19).

AGRADECIMIENTOS. Al PROMEP por el apoyo brindado para el proyecto Taxonomía y Manejo de Moscas Blancas. A Antonio Macías Flores por los comentarios realizados al presente trabajo y muestras de Bemisia tabaci del estado de Nayarit proporcionadas. A Patricia Rojas Rojas y a Carla Sánchez Hernández por los especímenes enviados y por su interés en este estudio. 




Fig. 22. Trialeurodes vaporariorum, placas de cera en abdomen de hembra, vista ventral.

\section{LITERATURA CITADA}

Azab, A. K., Megahed, M. M. \& El-Mirsawi, H. D. 1969. Studies on Bemisia tabaci (Genn.). Bulletin of the Entomological Society of Egypt, 53: 339-353.

Bink, F. A. 1979. Methods for mounting Aleyrodidae specimens. Entomologische Berichten, 39:158160.

Brown, J. K. \& Nelson, M. R. 1988. Transmission, host range, and virus-vector relationships of chino del tomate, a whitefly--transmitted geminivirus from Sinaloa, Mexico. Plant Disease, 72: 866-869.

Carapia R., V. E. 1991. Mosquitas blancas asociadas al cultivo del tomate en Xalostoc, Mor. Mem. XXVI Congreso Nacional de Entomología. Veracruz, Ver. Mayo de 1991.

Gill, R. J. 1990. The morphology of whiteflies, pp. 47-90. In: Gerling, D. (Ed.). Whiteflies: their Bionomics, Pest Status and Management. Intercept, Ltd. Andover, Hants, U. K.

Hernández, R. F. 1972. Estudios sobre mosquita blanca, Trialeurodes vaporariorum (West.) en el estado de Morelos. Agricultura Técnica en México, 3: 165-172.

Hill, B. G. 1969. A morphological comparison between two species of whitefly Trialeurodes vaporariorum (West.) and Bemisia tabaci (Genn.) (Homoptera: Aleyrodidae) which occur on tobacco in the Transvaal. Phitophilactica, 1: 127-143.

Martin, J. H. 1987. An identification guide to common whiteflies pest species of the World (Homoptera:Aleyrodidae). Tropical Pest Management, 33:298-322.

Lima, A. C. S., Lara, F. M. \& Dos Santos, E. J. M. 2001. Morfología da mosca branca, Bemisia tabaci biotipo"B" (Hemíptera: Aleyrodidae), encontradas em jabotical, SP, com base em electron-micrografias de barredura. Boletín de Sanidad Vegetal. Plagas, 27: 315-322.

Russell, L. M. 1947. A classification of the whiteflies of the new tribe Trialeuridini (Homoptera: Aleyrodidae). Revista de Entomologia, 18: 1-44.

Russell, L. M. 1948. The North American Species of the genus Trialeurodes. United States Department of Agriculture Miscellaneous Publication, 635: 1-85. 